J. Clin. Chem. Clin. Biochem.

Vol. 18, 1980, pp. $355-361$

\title{
Die Bestimmung von Progesteron im Harn mit der kompetitiven Proteinbindungsmethode
}

\author{
Von F. Schön, K. Hackenberg, D. Paar und D. Reinwein \\ Aus der Abteilung für klinische Endokrinologie der Medizinischen Klinik und Poliklinik \\ (Direktor: Prof. Dr. D. Reinwein) der Universität Essen (GHS)
}

(Eingegangen am 2. August 1979/21. Januar 1980)

Herm Prof. Dr. O. H. Amold zum 70. Geburtstag gewidmet

Zusammenfassung: Es wird über eine neue Methode zur Progesteronbestimmung im Harn nach dem Prinzip der kompetitiven Proteinbindung berichtet. Bei einer Nachweisgrenze für Progesteron von 0,24 $\mu \mathrm{g} / 1$ Urin liegen die Variationskoeffizienten in der Serie bei 4-10\% und von Tag zu' Tag bei 9,3-17\%. Die Wiederfindung von zugesetztem Progesteron beträgt 104,3\%. Bei 8 gesunden Männern liegt die Progesteronausscheidung im Harn bei durchschnittlich $0,12 \pm 0,10 \mu \mathrm{g} / \mathrm{g}$ Kreatinin. Bei 7 gesunden Frauen mit normalem Menstruationszyklus beträgt die Progesteronausscheidung in der Follikelphase 1,4 $\pm 1,1 \mu \mathrm{g} / \mathrm{g}$ Kreatinin und in der Lutealphase 7,7 $\pm 4,6 \mu \mathrm{g} / \mathrm{g}$ Kreatinin. 175 Sammelurine gesunder Schwangerer zeigen im Verlauf der ungestörten Schwangerschaft einen hochsignifikanten Anstieg $(\mathrm{y}=-11,1+1,1 \mathrm{x}, \mathrm{r}=0,66, \mathrm{p}<0,001)$ von 1,5 auf $25,7 \mu \mathrm{g} / \mathrm{g}$ Kreatinin.

\section{Determination of progesterone in urine by a competitive protein binding method}

Summary: A new method, based on the principle of competitive protein binding, is described for the determination of progesterone in urine. The sensitivity of the assay for progesterone is $0.24 \mu \mathrm{g} / \mathrm{l}$ urine. The within-assay precision, as determined by the coefficient of variation, varies between 4 and $10 \%$, the between assay precision between 9.2 and $17 \%$. The recovery of progesterone is $104.3 \%$. The average urinary progesterone excretion in normal men is $0.12 \pm 0.10 \mu \mathrm{g} / \mathrm{g}$ creatinine. In the follicular phase of 7 normal women the urinary progesterone excretion is $1.4 \pm 1.1 \mu \mathrm{g} / \mathrm{g}$ creatinine, in the luteal phase $7.7 \pm 4.6 \mu \mathrm{g} / \mathrm{g}$ creatinine. In normal pregnancy the urinary progesterone excretion rises significantly $(\mathrm{y}=-11.1 \pm 1.1 \mathrm{x}, \mathrm{r}=0.66, \mathrm{n}=175, \mathrm{p}<0.001)$ from 1.5 to $25.7 \mu \mathrm{g} / \mathrm{g}$ creatinine.

\section{Einführung}

Obwohl Ismail \& Harkness 1967 (1) und van der Molen \& Corpechot 1968 (2) niedrige Progesteronkonzentrationen im Harn Schwangerer nachweisen konnten, wurde unseres Wissens bisher keine Routinemethode zur Progesteronbestimmung im Harn beschrieben. Lediglich Stiefel \& Ruse (3) berichteten über eine Doppelisotopen=Methode zur Bestimmung von 16 $\alpha$-Hydroxyprogesteron im Schwangerenharn.

Im folgenden sollen eine Methode zur Bestimmung des Progesterons ${ }^{1}$ ) im Harn mit der kompetitiven Proteinbindungsmethode beschrieben und die Normalwerte für gesunde Männer, Frauen mit ovulatorischen Zyklen und gesunde Schwängere dargestellt werden.

1) Abkürzungen und Hormone:

CBG = Corticosteroid-bindendes Globulin, Progesteron = 4Pregnen-3,20-dion, 17 $\alpha$-Hy droxyprogesteron $=17 \alpha$-Hy droxy4-pregnen-3,20-dion, $20 \alpha$-Dihydroprogesteron $=20 \alpha$-Hydroxy4-pregnen-3,20-dion, Cortisol $=11 \beta, 17,21-$ Trihydroxy-pregnen3,20-dion.

\section{Material und Methoden}

\section{Reagenzien}

[1,2- $\left.{ }^{3} \mathrm{H}\right] \mathrm{Hydrocortison}$ der Firma New England Nuclear (Lot.Nr. 853-104), spezifische Aktivität $37 \mathrm{MBq} / 7 \mu \mathrm{g}(1 \mathrm{mCi} / 7 \mu \mathrm{g})$.

Zur Herstellung der Stammlösung werden $37 \mathrm{MBq} / \mathrm{ml}$ auf $50 \mathrm{ml}$ Benzol/Ethanol $(45 \mathrm{ml}+5 \mathrm{ml})$ gegeben und bei $4{ }^{\circ} \mathrm{C}$ aufbewahrt. $\left[4^{14} \mathrm{C}\right]$ Progesteron (Code CFA, Batch 38) der Fa. Radiochemical Centre Amersham, Buckinghamshire mit einer spezifischen Aktivität von $2246 \mathrm{MBq} / \mathrm{mmol}$ entsprechend $7 \mathrm{MBq} / \mathrm{mg}(60,7 \mathrm{mCi}$ ) mmol $=192 \mu \mathrm{Ci} / \mathrm{mg}$ ). Die radiochemische Reinheit beträgt nach Angaben des Herstellers $98 \%$.

Progesteron (Nr. 24614, Fa. Merck). Als Stammlösung lösten wir $10 \mathrm{mg}$ Progesteron in $100 \mathrm{ml}$ Methanol, die im Kühlschrank gelagert wurde. Die Standardlösung setzten wir für jede Bestimmung frisch an, indem wir $10 \mu \mathrm{l}$ der Stammlösung in $100 \mathrm{ml}$ Methanol lösten.

Das Lösungsmittel Petroleumbenzin (p.a., Nr. 1775) mit einem Siedebereich $40-60^{\circ} \mathrm{C}$ von der Fa. Merck, Darmstadt, wurde ohne weitere Vorreinigung verwendet.

Als Szintillationsflüssigkeit verwenden wir Unisolve-1 der $\mathrm{Fa}$. Zinsser, Frankfurt. Nach Angaben des Herstellers wird bei Einsatz von $1 \mathrm{ml}$ Wasser und $10 \mathrm{ml}$ Unisolve-1 bei $5^{\circ} \mathrm{C}$ eine $\mathrm{Zähl}$ ausbeute von $41 \%$ für ${ }^{3} \mathrm{H}$ und von $88 \%$ für ${ }^{14} \mathrm{C}$ erzielt.

Aktivkohle Norit A Serva-Labor, Heidelberg. 
Dextran T 70 mit einem Molekulargewicht von 70000 der Fa. Pharmacia, Uppsala.

Kohle-Dextran-Suspension: Zur Herstellung der gebrauchsfertigen Suspension werden $2 \mathrm{ml} 5 \mathrm{~g} / \mathrm{l}$ Dextranlösung und $2 \mathrm{ml}$ $0,5 \mathrm{~g} / \mathrm{l}$ Charcoal Norit A-Suspension in $56 \mathrm{ml}$ physiologischer Natriumchlorid-Lösung gelöst. Vor Gebrauch wird die Lösung unter Eiskühlung gemischt.

\section{Geräte}

An Geräten werden benötigt: Kolbenhub-Pipetten (Eppendorf), ein Vakuum-Trockenschrank ( $\mathrm{Fa}$. Heraeus), einen Schüttelmixer „Whirlimixer" (Fa. Fisons, Leicestershire), ein Vertikalschüttler (Fa. Degussa, Heidelberg), eine Repetierspritze „Ultra - Asept“ $2 \mathrm{ml}$ der Firma Sartorius, Göttingen, Extraktionsgläser $10 \mathrm{ml}$ mit Schliffstopfen und Reagenzgläser mit rundem Boden (Maße $75 \times 11-11,5 \mathrm{~mm}$ ) der Fa. Scherf, Polyethylen-Zählflaschen der Fa. Zinsser, Frankfurt, mit einem Nulleffekt von $10 \mathrm{Imp} . / \mathrm{min}$, Kühlzentrifuge MSE Mistral 6L (Measuring and Scientific Equipment, London) sowie ein Tricarb-Liquid-Szintillationszähler, Packard Typ 2450.

\section{Bindungsserum}

Für die Herstellung des Bindungsserums werden einem gesunden Blutspender, der am Vorabend $3 \mathrm{mg}$ Dexamethason erhielt, $500 \mathrm{ml}$ Blut abgenommen und zentrifugiert. Das Serum wird in Portionen zu $5 \mathrm{ml}$ bei $-20^{\circ} \mathrm{C}$ eingefroren und erst kurz vor Gebrauch wieder aufgetaut. Im Laufe eines Jahres blieb die CBG-Aktivität bei unseren Versuchen konstant. Vor dem Einsatz des Bindungsserums muß durch Vorversuche die optimale CBG-Verdünnung ausgetestet werden. Die hierbei zu berücksichtigenden Punkte sind in Tabelle 1 aufgelistet.

Tab. 1. Faktoren, die bei der Austestung des Bindungsplasmas zu berücksichtigen sind $(5,6)$.

1. Natur und Menge des verwendeten Bindungsproteins

2. Verhältnis der Konzentrationen des Bindungsproteins, Tracers und nachzuweisenden Hormons zueinander

3. Affinitätsverhältnis des markierten und nicht markierten Hormons zum Bindungsprotein.

Eine Verwendung von $\left[{ }^{14} \mathrm{C} \mid \mathrm{Progesteron}\right.$ erwies sich als unbrauchbar, weil beim Einsatz von $\left[{ }^{14} \mathrm{C}\right]$ Progesteron wegen seiner geringen spezifischen Aktivität ( $1 / 1100$ der des $\left[{ }^{3} \mathrm{H}\right]$ Cortisols) die Bindungskapazität des $C B G$ überschritten wurde. Bei Einsatz von $\left({ }^{3} \mathrm{H}\right)$ Cortisol wurde bei einer $\mathrm{CBG}$-Verdünnung von $1: 300$ eine genügend große Impulsrate erzielt (etwa $15500 \mathrm{Imp} . / \mathrm{min}$ für den Nullwert), so daß der mittlere Zählfehler bei 1 Minute Zählzeit immer unter 2.0\% lag. Als beste BindungsplasmaZusammensetzung, mit der alle Urinbestimmungen sowie die Qualitätskontrolle erfolgten (siehe Standardkurve Abb. 1) ergab sich:

$$
\text { Verdünnung 1:300 }
$$$$
\left.0,045 \mathrm{ml} \mathrm{l}{ }^{3} \mathrm{H}\right] \text { Cortisol }
$$

\section{Probengewinnung}

Die Sammlung der 24-h-Urine wurde in der Regel einen Tag vor dem nächsten Vorstellungstermin durchgeführt. Die Unterweisung in das ordnungsgemäße Urinsammeln erfolgte mündlich während der Beratung. Außerdem wurde eine Sammelanweisung mitgegeben.

Das Volumen der ohne Zusatz gesammelten Urine wurde sofort gemessen und jeweils eine Probe von $50 \mathrm{ml}$ bei $-20^{\circ} \mathrm{C}$ eingefroren. Tiefgefroren gelagert soll die Steroidkonzentration nach Murphy (4) unverändert bleiben. Werden die Urinproben bei kühler Raumtemperatur stehen gelassen, so steigt nach 6 Tagen der Progesterongehalt auf $110 \%$ des ursprünglichen Gehaltes

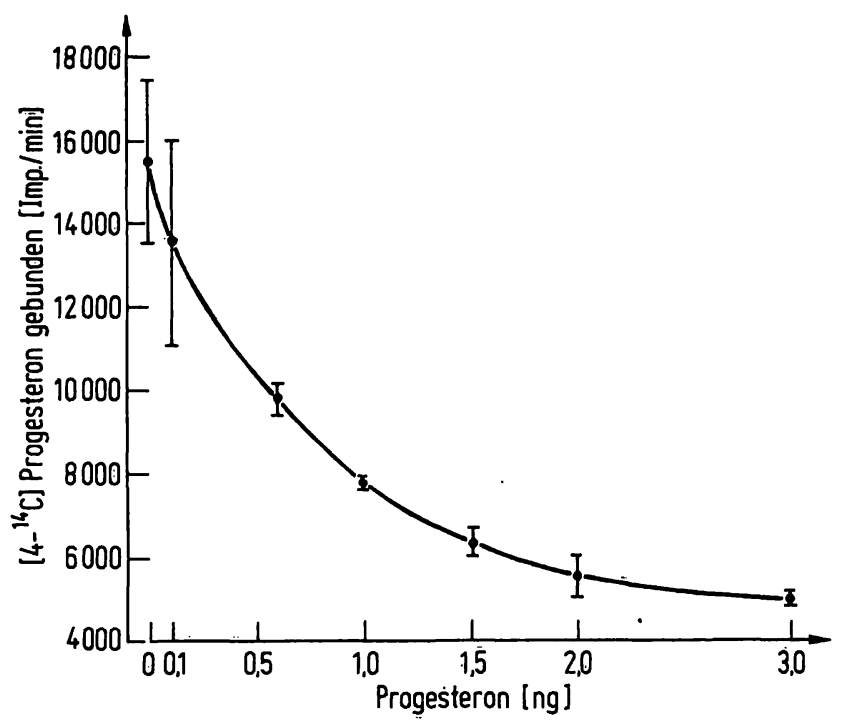

Abb. 1. Typische Progesteron-Standardkurve für den Meßbereich 0-3 ng. Standardabweichung intraassay bei Dreifachbestimmung und 1 Minute Zählzeit. BindungsplasmaZusammensetzung: Verdünnung 1:300, $0,045 \mathrm{ml}$ $\left[{ }^{3} \mathrm{H}\right]$ Cortisol.

einer frisch untersuchten Probe an, nach 8 Tagen auf 120\%, nach 10 Tagen auf $171 \%$ (7).

Zur Errechnung der Progesteron-Kreatinin-Ratio wurden simultan in den Harnen die Kreatininkonzentrationen mit der Methode nach Folin \& $W u$, modifiziert für den Autoanalyzer I, Technicon, unter fortlaufender Qualitätssicherung ermittelt.

\section{Statistische Methoden}

Für die Angaben des arithmetischen Mittelwertes, der Standardabweichung und des Variationskoeffizienten wurden die üblichen Formeln verwendet. Die Berechnung des Mittelwertes und des 95\%-Vertrauensbereiches logarithmisch verteilter Parameter erfolgte nach den Formeln von Sachs (8). An statistischen Tests wurden durchgeführt

1. der t-Test nach Student für verbundene Stichproben zur Signifikanzprüfung der Progesteronwerte für die entsprechenden Zeitintervalle,

2. den $\chi^{2}$-Test zur Prüfung der Signifikanzen von Häufigkeiten,

3. der U-Test von Wilcoxon, Mann \& Whitney zur Prüfung auf Signifikanz der Differenz der ermittelten Medianwerte bei Gestosen und gesunden Schwangeren.

Zur Berechnung der Stärke des Zusammenhanges zwischen 2 normalverteilten Variablen wurde der Korrelationskoeffizient $r$ ermittelt.

Die Bewertung der diagnostischen Empfindlichkeit und Spezifität erfolgte nach der Ergebnismatrix von Werner (9) und den Kriterien nach Oellerich (10).

\section{Ergebnisse}

\section{Durchführung der Bestimmung}

\section{Urinverdünnung}

Sammelurine mit einem hohen Progesterongehalt (Spätschwangerschaft) erfordern eine Verdûnnung mit $9 \mathrm{~g} / 1$ Natriumchlorid-Lösung, deren Leerwert sich im Assay nicht signifikant von Null unterscheidet (Tab. 2). Dabei ist die möglichst niedrige Verdünnung zuu wählen, 
und vom CBG gebunden werden. Durch Petroläther wird das im Serum vorhandene Progesteron zu 85,5 bis 97,5\% erfaßt (Tab. 3). in unserem Assay betrug die Wiederfindung von radioaktiv markiertem Progesteron im Petroläther $98,5 \%(7,11)$. Cortisol, Corticosteron und 11=Desoxycortisol beeinflussen die Methode nicht $(12,13)$. Die Wiederfindung von $\left[{ }^{3} \mathrm{H}\right]$ Cortisol betrug in unserem Assay $1,6 \%(n=8)$. Das Hauptabbauprodukt des Progesterons, das Pregnandiol, liegt im Harn überwiegend in glucuronidierter Form vor (14) und wird mit der Petroläther-Extraktion nicht erfaßt (15).

Tab. 3. Steroide, die mit der Petroläther-Extraktion erfaßt werden.

\begin{tabular}{lclll}
\hline Steroid & $\begin{array}{l}\text { Neill } \\
(31)\end{array}$ & $\begin{array}{l}\text { Murphy } \\
(17)^{*}\end{array}$ & $\begin{array}{l}\text { Johansson } \\
(12)^{*}\end{array}$ & $\begin{array}{l}\text { Reeves } \\
(29)\end{array}$ \\
\hline Progesteron & $90 \%$ & $97,3 \%$ & $85,5 \%$ & $86,5 \%$ \\
20 $\alpha$-Dihydroprogesteron & $90 \%$ & & $64 \%$ & $77,5 \%$ \\
$17 \alpha$-Hydroxyprogesteron & $40 \%$ & & $14 \%$ & $28,1 \%$ \\
Testosteron & & $84 \%$ & $28,5 \%$ & \\
Corticosteron & $1 \%$ & $16 \%$ & $<0,25 \%$ & \\
Cortisol & $1 \%$ & $8,8 \%$ & $<0,25 \%$ & \\
11-Desoxycortisol & & & $<0,25 \%$ & \\
\hline
\end{tabular}

* Wiederfindung mit radioaktiv markierten Steroiden.

Wegen ihrer geringen Bindungsaffinität zum CBG ist die Interferenz von $20 \alpha$-Dihydroprogesteron (16) und $17 \alpha$ Hydroxyprogesteron (17) zu vernachlässigen. Ebenso spielt Testosteron bei der Konkurrenz um die Bindungsstellen am CBG keine Rolle, da es trotz eines 5-10fachen Anstiegs im Serum Schwangerer (18) nur eine relative Bindungsaffinität zum $\mathrm{CBG}$ von $4 \%$, verglichen mit Cortisol, aufweist $(17,18)$.

\section{Rich tigkeit}

Die Richtigkeit ergibt sich aus der Wiederfindung von Progesteron in einem Urin mit einem Progesterongehalt von $1,76 \mu \mathrm{g} / 1$ Urin. Sie beträgt bei $\mathrm{n}=16 \mathrm{im}$ Durchschnitt 104,3\% (Tab. 4).

Tab. 4. Wiederfindung von Progesteron.

\begin{tabular}{llll}
\hline $\begin{array}{l}\text { Zusatz von } \\
\text { Progesteron } \\
\text { (ng) }\end{array}$ & $\begin{array}{l}\text { Progesteron } \\
\text { gemessen } \\
\text { (ng) }\end{array}$ & n Wiederfindung \\
\hline ohne & 1,76 & 5 & - \\
0,5 & 2,40 & 6 & $0,64: 0,50=128 \%$ \\
1,0 & 2,69 & 6 & $0,97: 1,00=97 \%$ \\
2,0 & 3,60 & 4 & $1,84: 2,00=92 \%$ \\
\hline
\end{tabular}

\section{Präzision}

Aufgrund der Intraassay-Streuung der Werte der Standardkurve beträgt die Präzision zwischen 4 und $10 \%$ für den Bereich der Kurve, in dem abgelesen wird.
Die Intraassay-Präzision der Urinbèstimmungen liegt zwischen 2,1 und 6\% (Tab. 5). Bei der Streuung von Tag zu Tag (interassay) liegt der Variationskoeffizient für den Meßbereich der Kurve im Durchschnitt bei $12,9 \%$ (Bereich von 9,3-18\%) und fur die Kontrollurine (Tab. 6) bei 5,7\% (Bereich 3,3-8,0\%).

Tab. 5. Intraassay - Präzision.

\begin{tabular}{llc}
\hline $\begin{array}{l}\text { Progesteron } \\
\text { (ng) }\end{array}$ & $\begin{array}{l}\text { s } \\
\text { (ng) }\end{array}$ & $\begin{array}{l}\text { VK } \\
(\%)\end{array}$ \\
\hline Standárdkurve (3-fach Bestimmung) & \\
0,1 & 0,04 & 40 \\
0,5 & 0,035 & 6,9 \\
1,0 & 0,1 & 10 \\
1,5 & 0,06 & 4 \\
2,0 & 0,16 & 8 \\
3,0 & 0,23 & 7,7 \\
Urin (5-fach. Bestimmung) & &. \\
1,63 & 0,097 & 6,0 \\
14,42 & 0,31 & 2,1 \\
\hline
\end{tabular}

Tab. 6. Interassay - Präżision

\begin{tabular}{lll}
\hline $\begin{array}{l}\text { Progesteron } \\
\text { (ng) }\end{array}$ & $\begin{array}{l}\text { s } \\
\text { (ng) }\end{array}$ & $\begin{array}{l}\text { VK } \\
(\%)\end{array}$ \\
\hline Standardkurve (3-fach Bestimmung) & \\
0,1 & 0,039 & 39 \\
0,5 & 0,09 & 18 \\
1,0 & 0,17 & 17 \\
1,5 & 0,14 & 9,3 \\
2,0 & 0,21 & 10,5 \\
3,0 & 0,30 & 10 \\
& & \\
Kontrollurine & & \\
5,3 & 0,29 & 5,5 \\
10,0 & 0,6 & 6,0 \\
14,1 & 1,13 & 8,0 \\
5,98 & 0,2 & 3,3 \\
\hline
\end{tabular}

\section{Nach weisgrenze}

Die Nachweisgrenze ergibt sich aus dem Null-Nanogramm-Wert plus $3 \mathrm{~s}$. Sie beträgt $0,24 \mu \mathrm{g} / 1$ Progesteron.

\section{Prak tikabilität}

Im Rahmen unserer Versuchsreihe führten wir etwa 900 Progesteronbestimmungen im Harn durch. Dabei erwies sich die Methode als praktikabel und kostengünstig. Der Umfang einer Analysenserie wird durch die Trocknergröße und die Kühlzentrifugeneinsätze beschränkt. Für die Bestimmung von 19 Urinen als Doppelbestimmungen einschließlich Kontrollurin und Standardkurve als 3-fach-Bestimmung benötigen wir ohne Zählen im Tricarb etwa 5-6 Stunden. Die Materialkosten für eine Bestimmung betragen im Mittel 1,50 bis $2,00 \mathrm{DM}$. 


\section{Referenzwerte}

Bei gesunden Männern $(n=8)$ liegt die Progesteronausscheidung bei $0,12 \pm 0,10 \mu \mathrm{g} / \mathrm{g}$ Kreatinin (siehe Abb. 3). Bei Frauen mit normalem Menstruationszyklus ist die Ausscheidung des Progesterons in der Lutealphase mit $7,7 \pm 4,6 \mu \mathrm{g} / \mathrm{g}$ Kreatinin signifikant höher als in der Follikelphase mit $1,4 \pm 1,1(n=7, p<0,005)$. Die 7 untersuchten Probandinnen zeigten eine deutliche Erhöhung der Progesteronausscheidung im 24-h-Urin vom 8.-10. zum 18.-22. Zyklustag (Abb. 3).

Die Progesteronausscheidung im Harn bei 175 gesunden Schwangeren zeigt eine logarithmische Normalverteilung (7). Die Progesteron-Kreatinin-Ratio steigt im Verlauf der ungestörten Schwangerschaft hochsignifikant an $(\mathrm{p}<0,001, \mathrm{y}=-11,1+1,1 \mathrm{x}, \mathrm{r}=0,66, \mathrm{n}=175)$. Mittelwerte und $95 \%$-Vertrauensbereich siehe Abbildung 4 und Tabelle 7.

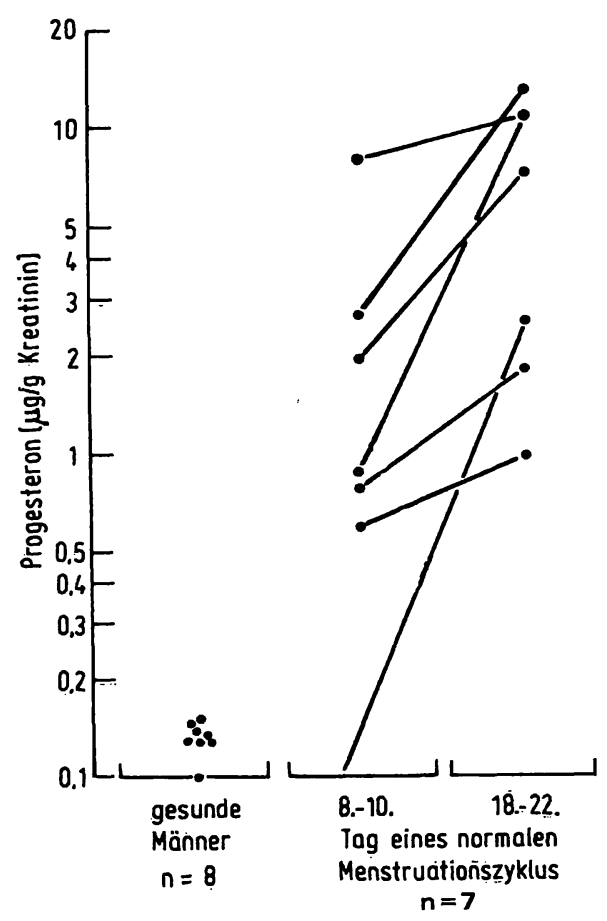

Abb. 3. Normalwerte der Progesteronausscheidung gesunder Männer $(n=8)$ und Frauen $(n=7)$ im Härn in $\mu \mathrm{g} / \mathrm{g}$ Kreatinin.

\section{Methodenkritik}

Um den Anforderungèen an Präzision, Richtigkeit und Empfindlichkeit $(10,21)$ zu genügen, müssen folgende kritische Schritte der Methode beachtet werden:

1. Herstellung eines geeigneten Bindungsserums

2. Standardisierter Extraktionsmodus

3. Einhaltung der Inkubationsbedingungen

Bei Verwendung von humanem CBG muß durch eine große Plasmaverdünnung die Bindungskapazität anderer Bindungsproteine wie Albumin und Orosomucoid redu-

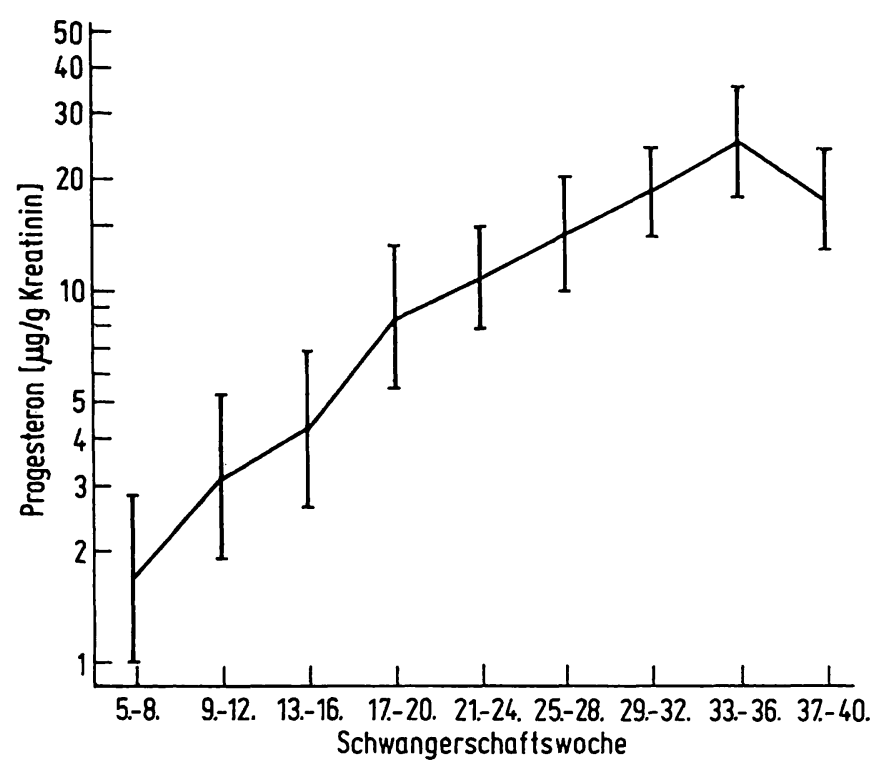

Abb. 4. Ausscheidung von Progesteron im Harn in $\mu \mathrm{g} / \mathrm{g}$ Kreatinin im Verlauf der normalen Schwangerschaft $(n=175)$. Die Balken geben den $95 \%$-Vertrauensbereich wieder.

Tab. 7. Mittelwerte und 95\%-Vertrauensbereich der Progesteronausscheidung in $\mu \mathrm{g} / \mathrm{g}$ Kreatinin bei 175 Schwangeren.

\begin{tabular}{|c|c|c|c|c|}
\hline $\begin{array}{l}\text { Schwanger- } \\
\text { schaftswoche }\end{array}$ & $\mathrm{n}$ & $\begin{array}{l}95 \%- \\
\text { Vertrauensbereich }\end{array}$ & $\overline{\mathbf{x}}$ & \\
\hline $\begin{array}{l}5 .-8 . \\
9 .-12 . \\
13 .-16 . \\
17 .-20 . \\
21 .-24 . \\
25 .-28 . \\
29 .-32 . \\
33 .-36 . \\
37 .-40 .\end{array}$ & $\begin{array}{r}8 \\
17 \\
17 \\
17 \\
21 \\
33 \\
20 \\
20 \\
22\end{array}$ & $\begin{array}{r}0-2,8 \\
1,9-5,2 \\
2,6-6,9 \\
5,4-13,4 \\
7,9-14,8 \\
10,1-20,3 \\
14,0-24,7 \\
18,3-36,0 \\
13,0-24,4\end{array}$ & $\left.\begin{array}{r}1,5 \\
3,1 \\
4,3 \\
8,5 \\
10,8 \\
14,4 \\
18,6] \\
25,7 \\
17,8\end{array}\right]$ & $\begin{array}{l}p<<0,001 \\
p<<0,001\end{array}$ \\
\hline $\begin{array}{l}\text { 1. Trimenon } \\
\text { 2. Trimenon } \\
\text { 3. Trimenon } \\
\text { gesamte } \\
\text { Schwanger- } \\
\text { schaft }\end{array}$ & $\begin{array}{l}30 \\
77 \\
68\end{array}$ & $\begin{array}{l}0-6,9 \\
3,9-27,7 \\
9,0-38,8\end{array}$ & $\begin{array}{r}2,6] \\
10,4] \\
18,7\end{array}$ & $\begin{array}{l}p<<0,001 \\
p<<0,001\end{array}$ \\
\hline
\end{tabular}

ziert werden $(12,15,22,23)$. Nach Austestung mehrerer Verdünnungen wählten wir für die Messung im 0 bis 3 ng-Bereich eine 1:300-Verdünnung, die noch einen Impulșabfall von mehr als $50 \%$ lieferte. Ein geeignetes Bindungsplasma für den Meßbereich $0-30 \mathrm{pg}$ konnte nicht gefunden werden. Dies scheint bei Verwendung von Hühnerplasma (17) oder Pferde-CBG (24), die eine weitaus höhere Progesteronaffinität aufweisen, eher möglich zu sein.

Die Menge an radioaktiv markiertem Cortisol, die dem Bindungsplasma zugegeben werden soll, hängt von der zu messenden Hormonkonzentration und von der aus meßtechnischen Gründen erforderlichen Zahl der Impulse pro Minute ab. $\left[{ }^{14} \mathrm{C}\right]$ Progesteron erwies sich wegen der zu geringen spez. Aktivität als nicht verwendbar. 
Die Extraktion des Progesterons aus dem Urin wurde mit Petroläther im Verhältnis $4+1$ (Petroläther + Urin) für genau 5 Minuten durchgeführt. Zwar wurde bisher in der Literatur ein Verhältnis von 10:1 empfohlen $(12,17)$, doch reicht der hier beschriebene Modus aus, um $98,5 \%$ von $\left[{ }^{14} \mathrm{C}\right]$ Progesteron zu erfassen $(7,11)$. Eine mehrfache Petroläther-Extraktion erweist sich als nicht erforderlich (25).

Da das CBG im Gegensatz zu Albumin bei der Reaktion mit Steroiden temperaturabhängig ist (26); müssen die Inkubationstemperaturen und -zeiten genau eingehalten werden. Eine Inkubationszeit von 5 Minuten bei $40{ }^{\circ} \mathrm{C}$ erweist sich als ausreichend, ebenso eine Inkubation von 20 Minuten (27) bei $0^{\circ} \mathrm{C}$. Nach Westphal (28) ist bei niedrigen Temperaturen die Bindungsaffinität des CBG gegenüber Progesteron am größten. Nach unseren Erfahrungen reichen Inkubationszeiten unter 15-17 Minuten zur Gleichgewich tseinstellung nicht aus.

Wird Charcoal als Adsorbens verwendet, ist zu berücksichtigen, daß

1. die Spezifität der Methode beeinflußt wird,

2. zunehmende Charcoalmengen die Standardkurve senken (17) und

3. bei Verlängerung der Adsorptionszeit die Standardkurve abflacht.

Wird die Kontaktzeit mit der Kohle-Dextran-Suspension über 10 Minuten ausgedehnt, werden falsch hohe Progesteronkonzentrationen im Harn gemessen.

Für die Spezifität der Progesteronmethode müssen keine Einschränkungen gemacht werden. Neben Progesteron können nur Testosteron, $20 \alpha$-Dihydroprogesteron und $17 \alpha$-Hydroxyprogesteron interferieren (Tab. 3) $(5,12$, 17, 29). Testosteron wird in so geringen Mengen im Harn Schwangerer ausgeschieden (18), daß seine Interferenz im Streubereich der Methode liegt. Über die renale Ausscheidung von $20 \alpha$-Dihydro- und $17 \alpha$-Hydroxyprogesteron liegen keine Angaben vor. Wird 17 $\alpha$-Hydroxyprogesteron in freier Form ausgeschieden, dürfte es nur im 1. Trimester interferieren, da es nach einem Inkretionsmaximum in der 3. Schwangerschaftswoche nach der 16. Schwangerschaftswoche nur noch in Konzentrationen von $20 \mu \mathrm{g} / 1 \mathrm{im}$ Blut vorkommt. Inwieweit $16 \alpha$ Hydroxyprogesteron und Pregnenolon, die gegen Ende der Schwangerschaft vermehrt renal ausgeschieden werden, im Assay interferieren, muß vorerst offen bleiben.

Bei Reduktion von Sammelfehlern des 24-h-Urins durch Angabe der Progesteron-Kreatinin-Ratio (20) und Vermeidung der erwähnten Störfaktoren der Analyse (7) erweist sich die Bestimmung des Progesterons im Ham als eine empfehlenswerte Methode, die die Beurteilungskriterien einer zuverlässigen analytischen Methode (21, 30) erfüllt. Den Nachteilen einer relativ langen Analysendauer und der Austestung des Bindungsplasmas stehen die Vorteile der Spezifität und geringen Kosten gegenüber.

\section{Klinische Anwendung}

Nach ersten klinischen Erfahrungen $(7,11,19)$ kann die Bestimmung der Progesteronausscheidung im Ham zum Nachweis der Ovulation und zur Schwangerschaftsüberwachung eingesetzt werden.

Die 7 untersuchten Patientinnen mit ovulatorischen Menstruationszyklen zeigten nach der Ovulation eine hochsignifikant höhere Progesteronausscheidung als vor dem Ovulationszeitpunkt, so daß eine entsprechende Erhöhung der Progesteronausscheidung im Harn als Hinweis auf eine Ovulation gewertet werden kann. Die Sammelperiode (24 Stunden bzw. 8 Stunden) hat keinen Einfluß auf die ermittelten Progesteronwerte, sofern die Ausscheidung als Progesteron-Kreatinin-Ratio auf Kreatinin bezogen wird (20).

Zum anderen kann die Progesteronbestimmung im Harn als Kenngröße des placentaren Funktionszustandes zur Schwangerschaftsüberwachung eingesetzt werden (19). Erniedrigte Progesteronwerte im Harn gehen signifikant $\left(\mathrm{p}<0,05, \mathrm{n}=38, \chi^{2}\right)$ mit emiedrigten Konzentrationen von Human-Placenta-Lactogen im mütterlichen Blut einher. Bei Patientinnen mit Edema-Proteinuria-Hypertension-Gestosen liefert die Progesteronbestimmung im Harn in $65 \%$ richtig-positive Ergebnisse.

\section{Literatur}

1. Ismail, J. \& Harkness, R. A. (1967), Acta Endocrinol. (Kbh.) $56,272$.

2. Molen, H. J. van der \& Corpechot, C. (1968), J. Clin. Endocrinol. Metab. 28, 1361-1366.

3. Stiefel, M. \& Ruse, J. L. (1969), J. Clin. Endocrinol. Metab. 29, 7-11.

4. Murphy, B. E. P. (1970), Acta Endocrinol. (Kbh.) Suppl. 147,37

5. Ekins, R. P. \& Newman, B. (1970), Acta Endocrinol. (Kbh.), Suppl. 147, 11-24.
6. Rodbard, D., Bridson, W. \& Rayford, P. L. (1969), J. Lab. Clin. Med. 74, 770.

7. Schön, F. (1977), Das freie Cortisol und Progesteron im Harn während der Schwangerschaft. Methodische Untersuchung zur kompetitiven Proteinbindungsmethode, Inaugural-Dissertation, Essen.

8. Sachs, L. (1975), Statistische Methoden, Springer Verlag Berlin, 4. Auflage.

9. Werner, M. (1977), Med. Welt 29, 1254-1257.

10. Oellerich, M. \& Haeckel, R. (1978), Med. Welt 21; 866-872. 
11. Bülle, J. R. (1978), Bestimmung der freien Harncorticoide und des freien Progesterons im Harn mittels kompetitiver Proteinbindungsme thode und radioimmunologische HPLBestimmung im Plasma bei Schwangeren mit EPH-Gestose, Inaugural-Dissertation Essen.

12. Johansson, E. D. B. (1969), Acta Endocrinol. (Kbh.) 61, $592-606$.

13. Breuer, H., Hamel, D. \& Krüskemper, H. L. (1975), Methoden der Hormonbestimmungen, Thieme Verlag Stuttgart.

14. Wyss, H. J. (1970), Östriol- und Pregnandiolau sscheidung in der zweiten Schwangerschaftshälfte, Huber Verlag Bern.

15. Johansson, E. D. B. (1969), Acta Endocrinol. (Kbh.) 61, 607-617.

16. Sommerville, I. F. \& Vetrano, G. (1975), in: Methods in investigation and diagnostic endocrinology (Berson, S. A., ed.) Vol. 3, 73-124, Amsterdam.

17. Murphy, B. E. P. (1967), J. Clin. Endocrinol. Metab. 27, 973-978.

18. Demisch, K., Grant, J. K. \& Black, W. (1968), J. Endocrinol. $42,447$.

19. Schön, F., Hackenberg, K. \& Fischer, W. M. (1980), in Vorber

20. Dickey, R. P., Besch, P. K., Vorys, N. \& Ullery, J. C. (1968), Am. J. Obst. Gynecol. 4, 591-594.
21. Reeves, B. D. \& Calhoun, D. W. (1970), Acta Endocrinol. (Kbh.), Suppl. 147, 6-10.

22. Köbberling, J. \& Mühlen, A. v. z. (1972), Z. Klin. Chem. Klin. Biochem. 10, 495-501.

23. Vermeulen, A. (1975), Bestimmung von Cortisol im Plasma durch die kompetitive Proteinbindung, in: Methoden der Hormonbestimmungen (Breuer, H., Hamel, D. \& Krüskemper, H. L., ed.) Thieme Verlag Stuttgart, 169.

24. Murphy, B. E. P. (1975), J. Clin. Endocrinol. Metab. 41, 1050.

25. Johansson, E. D. B. (1970), Acta Endocrinol. (Kbh.), Suppl. 147, 188-203.

26. Burton, R. M. \& Westphal, U. (1972), Metabolism 21, 253.

27. Murphy, B. E. P. (1969), Recent Progr. Hormone Res. 25, 563-566.

28. Westphal, U. (1966), Hoppe-Seyler Z. Physiol. Chem. 346, 234.

29. Reeves, B. D., Souza, M. L. A. de, Thomson, I. E. \& Diczfalusy, E. (1970), Acta Endocrinol. (Kbh.) 63, 225-241.

30. Wisser, H. (1977), Med. Welt 28, 1251-1254.

31. Neill, J. D., Johansson, E. D. B., Datta, J. K. \& Knobil, E. (1967), J. Clin. Endocrinol. Metab. 27, 1167.

Dr. med. F. Schön

Prof. Dr. med. K. Hackenberg

Priv.-Doz. Dr. med. D. Paar

Prof. Dr: D. Reinwein

Abteilung für klinische Endokrinologie der Medizinischen Klinik und Poliklinik der

Universität Essen (GHS)

Hufelandstr. 55

4300 Essen 
. 